\title{
Research Paper: The Effect of Correction Medial Knee Displacement During Drop Vertical Jump on Performance in Male Basketball Athletes
}

\author{
Hemn Mohammadi ${ }^{*}$, Hassan Daneshmandi², Mohammad Hosein Alizadeh ${ }^{3}$
}

1. Department of Physical Education, Faculty of Humanities and Social Sciences, University of Kurdistan, Sanandaj, Iran.

2. Department of Sports Injury and Corrective Exercise, Faculty of Physical Education and Sport Sciences, University of Guilan, Rasht, Iran.

3. Department of Sport Medicine and Health, Faculty of Physical Education and Sports Sciences, University of Tehran, Tehran, Iran.

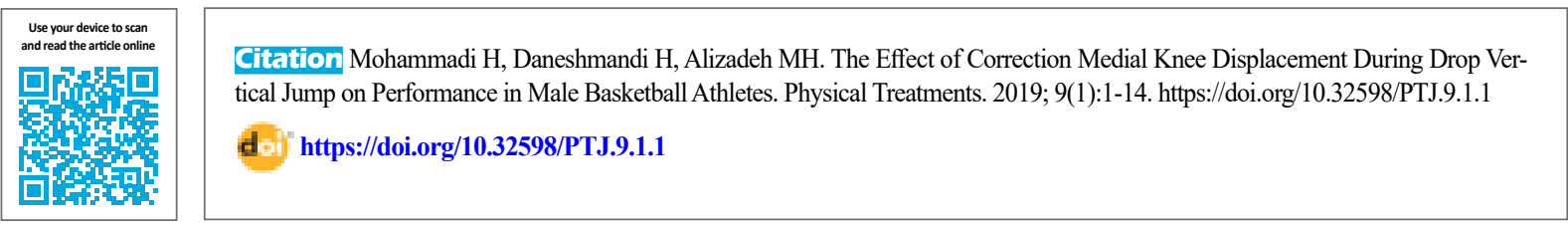

(C) 03

Article info:

Received: 10 Apr 2018

Accepted: 25 Oct 2018

Available Online: 01 Jan 2019
Keywords:

Athletic performance, Knee, Valgus, ACL, Basketball, Drop vertical jump

\begin{abstract}
A B S T RA C T
Purpose: Anterior Cruciate Ligament (ACL) injury is among the most prevalent knee injuries among young athletes, aged $15-25$ and occurs in $70 \%$ through a noncontact mechanisms. Medial Knee Displacement (MKD) is the key risk factor of ACL injury in basketball athletes. The present study investigated the effect of an MKD corrective exercises program on knee kinematics during Drop Vertical Jump (DVJ), and its performance in male basketball players.
\end{abstract}

Methods: The study participants consisted of 32 male basketball players (Mean \pm SD age: $20.8 \pm 1.7$ years, weight $74.0 \pm 5.2 \mathrm{~kg}$, height $183.9 \pm 5.0 \mathrm{~cm}$, body mass index $21.86 \pm 1.19 \mathrm{~kg} /$ $\mathrm{m}^{2}$, and experience $8.75 \pm 1.42$ years) with MKD during Double Leg Squat (DLS) test. The subjects were randomly placed into two groups (training, $n=16$, control, $n=16$ ). Training group participated in 10 sessions of the corrective exercise program. Pre-test and post-test assessments included knee kinematic during DVJ and performance test (Y balance and hop) in the dominant leg.

Results: The analysis of covariance test results revealed that the effects of the Pre-test, as well as the effects of groups on the post-test variables in the training group, were statistically significant $(\mathrm{P}<0.01)$ for all variables, except for knee flexion angle. Additionally, the training group experienced significant improvements $(\mathrm{P}<0.01)$ in kinematic variables during DVJ, such as reduced MKD in the pre-land frame $\left(4.32^{\circ}\right)$ and reduced MKD in a land frame $\left(5.51^{\circ}\right)$. They also indicated significant improvements $(\mathrm{P}<0.01)$ in performance variables, such as increased total $\mathrm{Y}$ balance test $(3.33 \mathrm{~cm})$, increased single hop test $(13.25 \mathrm{~cm})$, increased triple hop test $(22.25 \mathrm{~cm})$, increased crossover hop test $(19.81 \mathrm{~cm})$, and reduced $(0.23 \mathrm{~s}) 6$ meter timed hop test scores.

Conclusion: Due to the correction key risk factors of noncontact ACL injury Medial Knee Displacement (MKD), improved landing kinematic and increased performance, it seems that in male basketball players with MKD, this corrective exercises program can help to prevent noncontact knee injuries caused by MKD during functional activities like DVJ; it can also help to improve performance.

\footnotetext{
* Corresponding Author:

Hemn Mohammadi, PhD.

Address: Department of Physical Education, Faculty of Humanities and Social Sciences, University of Kurdistan, Sanandaj, Iran. Phone: +98 (87) 33662288

E-mail: hemn.m.64@gmail.com
} 


\section{Highlights}

- The corrective exercises can improve landing kinematic and increase performance in male basketball players with medial knee displacement.

- This exercises program can prevent noncontact knee injuries caused by medial knee displacement during functional activities like drop vertical jump.

\section{Plain Language Summary}

The purpose of this study was to investigate the effect of correction of medial knee displacement during drop vertical jump on the performance of male basketball athletes. After participating in 10 sessions of the corrective exercise program, the basketball players experienced significant improvements in kinematic variables during drop vertical jump (such as reduced medial knee displacement) and also significant improvements in performance variables. The implications of this study might suggest that personal trainers, coaches, and basketball players employ this corrective exercise program to improve knee kinematic during drop vertical jump and enhance athletes' performance.

\section{Introduction}

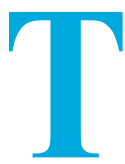

he placement of knee joint at the midpoint of lower extremity kinetic chain imposes excessive pressure to the knee in sport tasks, especially during weightbearing activities [1]. The specific mechanical behavior of the proximal and distal structures of the knee joint determines the correct or incorrect distribution of the forces imposed on the knee musculoskeletal system [1]. Accordingly, the ability of an athlete to maintain the correct alignment of the lower extremities segment through different movement planes can be a key risk factor for knee injuries during sports activities [1]. The dysfunction of lower extremity neuromuscular control can increase the amount of knee valgus and lead to Anterior Cruciate Ligament (ACL) injuries [2]. In other words, neuromuscular dysfunction is the most important risk factor for noncontact ACL injuries in basketball athletes [2]. During sports activities, it increases the load on the lower extremities joints and causes ACL injuries [2].

The incidence of sports injuries was evaluated in college athletes from 1993 to 2013 . The obtained data suggested that the most common injuries in indoor sports such as basketball and volleyball were ACL sprain; these had the highest number of cases treated with surgery and a longer average withdrawal time [3]. In addition to the high cost of treatment, ACL injuries result in the loss of sports participation and even losing season; they also create secondary injuries such as osteoarthritis (an increase of more than 10 times), meniscal tear, as well as psychological problems in athletes [4]. At least two- thirds of ACL sprains occur during noncontact situations such as cutting, pivoting, accelerating, decelerating, and landing from a jump [5]. The prevalence of ACL sprain is 68.6 per 100000 person-years. It is higher in males (81.7 vs. 55.3 per 100,000$)$; also the peak incidence in males is between 19 and 25 years [6]. It seems that the effect of preventive exercise programs on ACL injury depends on the field of sport. Because these programs cannot reduce the incidence of ACL injuries in basketball, but decrease those by $24 \%$ in football [7]. The mechanism of injury may be responsible for achieving the conflicting results of a preventive exercise program in various sports fields. This is because the mechanism of ACL injury in football is often due to contact between players; however, in basketball, it often occurs by noncontact mechanisms, and it is caused by frequent jumps and lands [8].

Studies have reported that $22 \%$ of America's National Basketball League players have not been able to return to competition after ACL injury; $44 \%$ of basketball players who returned to competition, have demonstrated reduced efficiency in professional performance [8]. Moreover, an ACL injury is the most severe basketball injury [9]. In addition to the high cost of ACL treatment, this injury results in secondary injuries like osteoarthritis in basketball players [4]. These factors have led researchers to develop programs to prevent ACL injury in basketball players and identify athletes at higher risks of it. Many studies investigated the neuromuscular deficiencies, mechanisms and the impact of exercise interventions on ACL injury [10-12]. Different ACL injury mechanisms have been reported; the most common mechanism is the frontal plane [12]. Hewett et al. in the video analysis of athlete injuries identi- 
fied 4 neuromuscular imbalances as the underlying mechanisms of noncontact ACL injuries; they included ligament dominance, quadriceps dominance, leg dominance, and trunk dominance [13]. In this study, among the common mechanisms, ligament dominance was selected due to its strong correlations with a noncontact ACL injury in basketball players $\left(r_{2}=0.88\right)$ [14].

The evaluation of risk factors for knee injuries by the threedimensional inverse dynamic method requires expensive and time-consuming laboratory techniques; thus, not all athletes can be evaluated by this method. Double Leg Squat (DLS) test is very practical and can be performed easily. Researchers can use the DLS test to screen neuromuscular imbalances in athletes $[15,16]$. They also used the DLS test for screening basketball players. According to the literature review, only one study was found that after identifying athletes with Medial Knee Displacement (MKD), investigated the effect of MKD corrective exercises program on the modulation of the kinematic factors of ACL injuries in basketball players [15]. In that study, only the effect of corrective exercises on the modification of some kinematic factors in female athletes during DLS test was investigated [15]. However, male basketball players were not investigated. It was also suggested to investigate the effect of MKD corrective exercises program during higher demand tasks like drop jump. Accordingly, the present study was conducted to investigate the effect of MKD corrective exercises program on knee kinematics during Drop Vertical Jump (DVJ) and performance in male basketball athletes.

\section{Materials and Methods}

Among male basketball athletes in Guilan Province, Iran, 32 players (training group $=16$, control group=16) with MKD who agreed to participate in the study were selected as subjects. The sample size was calculated based on the pilot study and previous literature [15]. Inclusion criteria consisted of 18-25 years of age, having at least a 5-year background of regular basketball practice, exercising at least 3 sessions per week, having normal body mass index $\left(20-25 \mathrm{~kg} / \mathrm{m}^{2}\right)$, MKD during DLS and correction MKD when heel lifts. Exclusion criteria consisted of an obvious deformity in the lower extremity (excessive anteversion, genu varum, genu valgum, tibial torsion, \& flatfoot), histories of trunk and lower extremity surgeries, sustainable lower extremity injury (e.g. knee degenerative changes and ankle instability), a history of ACL injury or severe lower extremity injury during the past year, and participation in ACL injury prevention exercise programs.

The information about the purpose and methodology of the research was provided to the athletes; they all provided informed consent before participation in the study. Demographic data, medical history and sports history of the subjects were collected using a questionnaire; then, the anatomical and anthropometric variables were measured. All measurements were conducted in Corrective Exercise Research Laboratory of the University of Guilan. After introducing and describing the performance tests (Y balance test, single hop test, triple hop test, crossover hop test and 6-meter timed hop test) DLS test, DVJ test, and a 10-minute warm-up were performed.

In the Pre-test, all of the above tests were recorded in three correct attempts. Then, the control group continued their usual daily activities without any special training. The training group participated in a 10 -session corrective exercises program. Most subjects completed three sessions per week, and all of them practiced in at least 2 sessions per week. Each training session lasted about 45 minutes. Finally, after completing the corrective exercise program, performance tests and DVJ test were performed for all athletes, similar to the first session conditions.

\section{Double Leg Squat (DLS) Test}

All basketball players were screened by DLS test (Figure 1) which consisted of 5 squats in standardized position (feet shoulder width apart, toes straight ahead, hands overhead with elbows locked). All athletes had visually identified MKD that was corrected when the second set of 5 squats was performed on heel lifts. MKD was considered present when the midpoint of the patella passed medial to the great toe in 3 of 5 squats $[15,17]$. Heel lifts when performing DLS was used to distinguish muscle imbalance in the hip and ankle joints. If MKD corrected when lifting the heel, the athlete was recognized as having weakness and stiffness of the ankle muscles [15, 17].

\section{Performance tests}

Performance tests consisted of Y balance test, single hop test, triple hop test, crossover hop test, and 6-meter timed hop test. Y balance test is valid and reliable (validity: 0.81 to $0.96 \&$ reliability: 0.79 to 0.91 ) to quantify dynamic postural control [18, 19]. Y balance test consists of 3 trials in each direction. In each trial, the athletes were instructed to reach as far as they could; then, return to the starting point while maintaining balance. In each reach trial, the maximum reach distance was recorded. Reach distances were normalized to each athletes' leg length. Normalized composite reach distance was computed as the sum of maximum reach distances in the 3 directions, divided by 3 times the limb length, and multiplied by 100 [18]. 


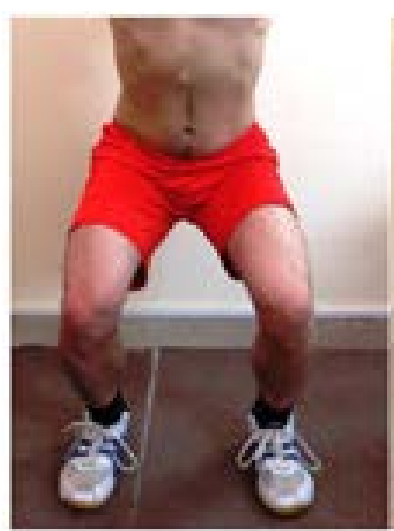

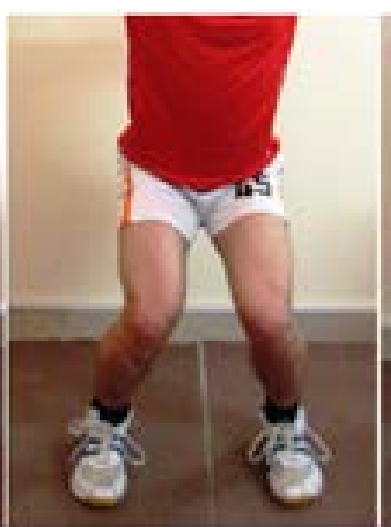

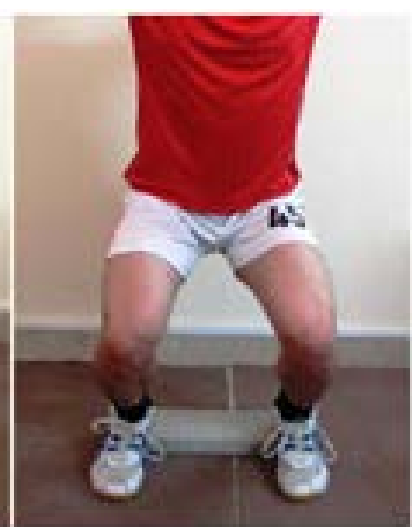

Figure 1. DLS Test

PHYSICAL TREA $\$ MENTS

A. Normal position; B. MKD position; C. Correction MKD.

Hop tests, like other tests, were performed in the basketball court. Two measuring tapes were fixed to the surface; one start line and another 6-meter line. Limb dominance was determined by asking athletes which limb they would use to kick a ball. To familiarize them with the hop test, athletes were requested to perform one submaximal trial of the first hop. Then, they performed three maximal trials that were recorded. The average value of the three trials was used for statistical analysis. The study participants had approximately 30 seconds rest between trials and approximately a minute rest between the tests $[19,20]$.

In triple crossover hop test, the athletes were requested to perform three crossover hops on one leg and control and hold the landing of the third hop for 3 seconds. In the triple hop test, the athletes performed three straight hops on one leg and control and hold the landing of the third hop for 3 seconds. The final score was equal to the sum of the distance of three hops. In the 6-meter timed hop test, the athletes performed 6-meter hops on one leg whit maximum speed. The final score was equal to the sum of the time duration of the 6-meter hops [19, 20].

\section{Drop Vertical Jump (DVJ) Test}

To perform the DVJ test (Figure 2), athletes started on top of a box ( $30 \mathrm{~cm}$ height) with feet positioned $35 \mathrm{~cm}$ apart. The athletes were instructed to drop directly down the box and immediately perform a maximum vertical jump, raising both arms as if they were jumping for a basketball rebound. Three successful trials were recorded for each subject [21]. The athletes performed jumping off the box, landing, and immediately performing a maximum vertical jump. This sequence was repeated 3 times. After the completion of the test, the researcher viewed all 3 trials, and the one that best represented the athlete's jumping ability was selected for kinematic assessment.

\section{Kinematic assessment}

DVJ kinematic were recorded by two cameras (Casio Japan, model CASIO-Ex-F1), with the ability to shoot 300 frames per second, and were evaluated using the Kinovea software. Cameras equipped with a memory stick were placed on a stand (110 cm height). The stand was positioned at $385 \mathrm{~cm}$ in front of a box $(30 \mathrm{~cm}$ height $)$. Furthermore, a Velcro circle $(2.5 \mathrm{~cm})$ was placed on each of the 8 corners of the box that faced the two cameras. A camera was used for measuring the frontal plane (MKD)

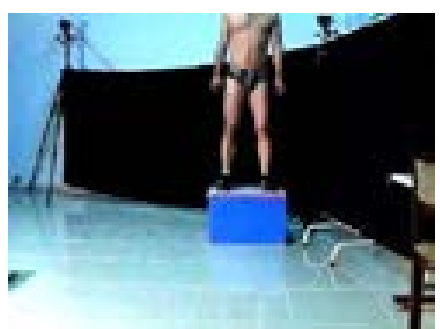

Figure 2. DVJ Test

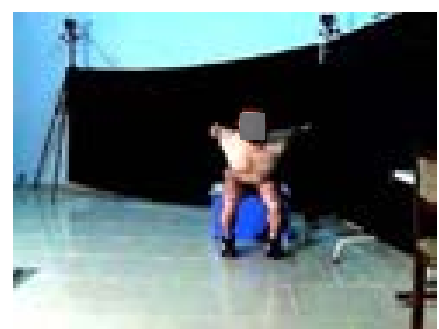

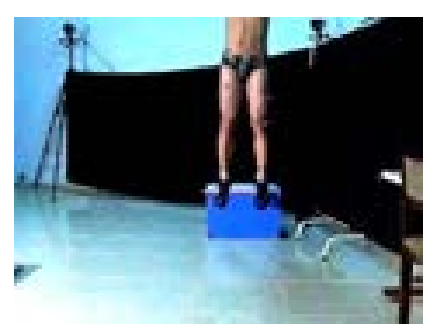

A. Start position; B. Drop from the box; C. Maximum vertical jump 
A
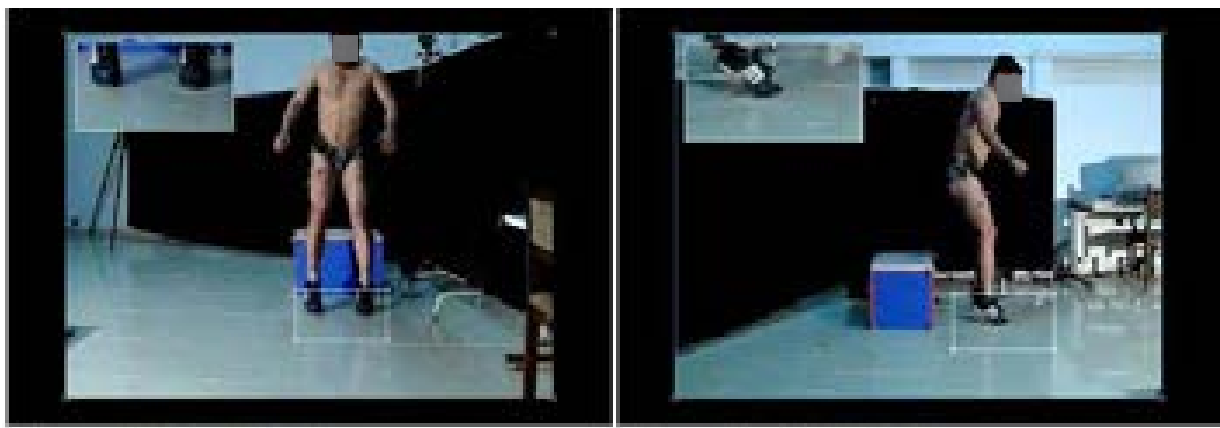

B
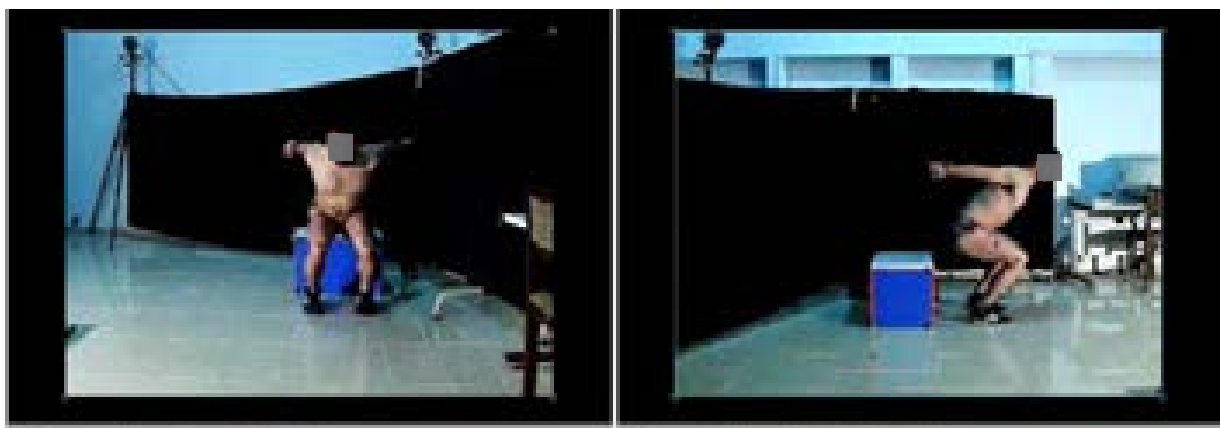

C
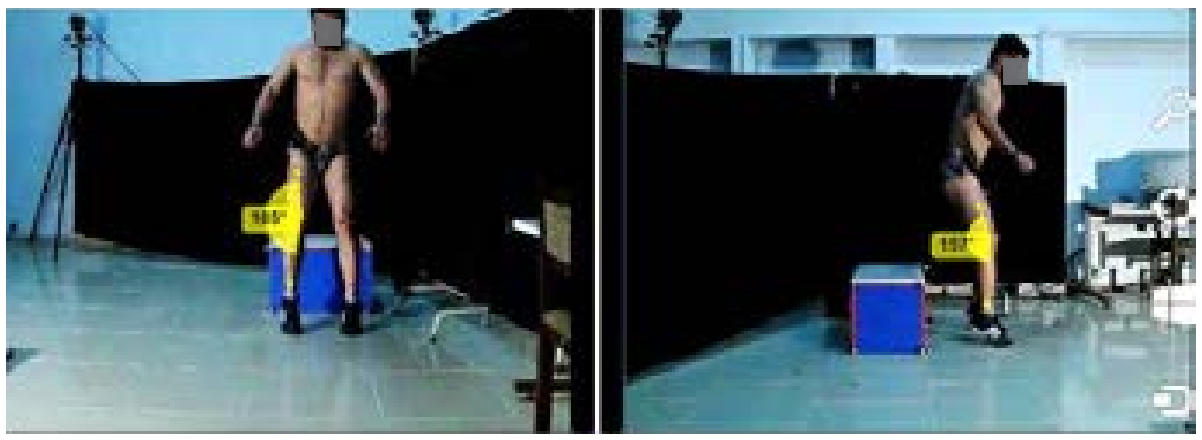

D
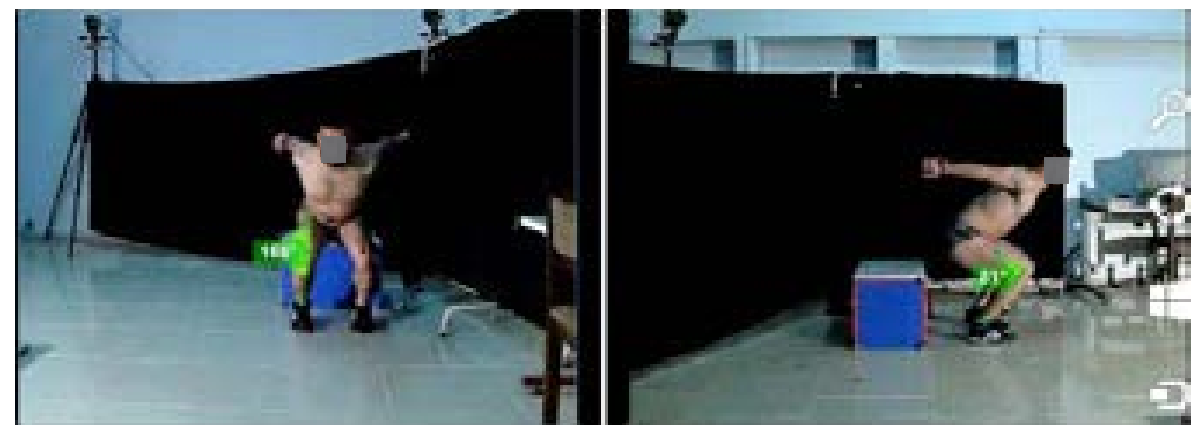

Figure 3. DVJ kinematics

PHYSICAL TREA TMENTS

A. Pre-land frame; B. Land frame; C. MDK and knee flexion in a pre-land frame; D. MDK and knee flexion in a land frame 
Table 1. The theoretical application of the applied corrective exercise program

\begin{tabular}{cc}
\hline Exercise Sequence & Muscles That Contributed in MKD \\
\hline Inhibit overactive muscles & Gastrocnemius, lateral hamstring, adductors \\
Lengthen tight muscles & Gastrocnemius, soleus, lateral hamstring, adductors \\
Strengthen weak muscles & Medial gastrocnemius, medial hamstring, tibialis posterior \\
Integration exercise & \\
\hline
\end{tabular}

and another one to assess the sagittal plane (knee flexion). Reflective markers were placed on both the right and left legs at the center of the mid-femur, the center of the patella, and the center of the talocrural joint for measuring MKD, as well as greater trochanter, lateral malleolus, and the center of each patella for measuring knee flexion. By advancing the video frame, two images were selected (pre-land, land).

The pre-land frame consisted of the frame in which the athlete's toes just touched the ground after the jump off from the box, and land frame consisted of the frame in which the athlete was at the deepest point. The pre-land frame was selected to represent the most fully extended position of the knee, and the land frame was selected because it represented the most out-of-control position during landing, and it was the deepest point of knee flexion. Then, the MKD angle and knee flexion were calculated in the frame pre-land and land frames. The synchronization of cameras was conducted using Kinovea software (Figure 3) [22, 23].

\section{Corrective exercises program}

Bell et al. applied corrective exercises protocol developed based on the National Academy of Sports Medicine Essentials of Corrective Exercise Training textbook $[15,24]$. Corrective exercises program was used to correct lower extremity alignments during functional tasks. Each athlete in the training group completed 10 exercise sessions in a 3-week period. All of them practiced in at least 2 sessions per week and each exercise session lasted about 45 minutes. In each session, exercises became more challenging with increasing sets, repetitions, or resistance or shifting to a new exercise. In this corrective exercise program, 5 exercises were focused on hip joint muscle and 5 on the ankle joint muscle.

Corrective exercises protocol was performed in a specific sequence that included inhibiting overactive muscles, lengthening tight muscles, strengthening weak muscles, and integrative exercise (Table 1, Figure 4). If athletes indicated that an exercise was becoming easier, a progression was made during the next session. Training group athletes completed 10 exercise sessions in 3 weeks. Posttesting in both groups was performed at 1 to 2 days after the final exercise session.

Equality of variance by Levene's test (Table 2) and normal distribution of data by Shapiro-Wilks are provided in Table 2. To determine the differences between the mean scores of the research variables, before and after conducting the corrective exercise program, the Paired-Samples t-test was used (Figure 5). To examine the effects of Pre-test and the effects of groups on the post-test variables in the training group, Analysis of Covariance (ANCOVA) was used (Table 2). After ensuring the normality of the data for each variable, the obtained data were analyzed by SPSS. The significance level was set at $\mathrm{P}<0.05$. Descriptive statistics were performed on all data. Mean \pm SD scores for all variables are listed in Table 3.

\section{Results}

The ANCOVA results indicated that the effects of the Pre-test, as well as the effects of groups on the post-test variables in training group, were significant $(\mathrm{P}<0.01)$ for all variables, except for the effects of groups on knee flexion angle. Moreover, Paired-Samples t-test suggested that after participation in corrective exercises program, the training groups experienced significant improvements $(\mathrm{P}<0.01)$ in kinematic variables during DVJ; reduced MKD in the pre-land frame (4.32 degree), reduced MKD in the land frame (6.51 degrees). Additionally, significant improvement was observed in performance variables $(\mathrm{P}<0.01)$; increased total $\mathrm{Y}$ balance test $(3 / 33 \mathrm{~cm})$, increased single hop test $(13 / 25 \mathrm{~cm})$, increased triple hop test $(22 / 25 \mathrm{~cm})$, increased crossover hop test $(19 / 81 \mathrm{~cm})$, and reduced $(0.23 \mathrm{~s})$ 6-meter timed hop test (Table 2 and 3).

\section{Discussion}

Participation in this corrective exercises program can result in a significant reduction $(\mathrm{P}<0.01)$ in the mean MKD value at initial contact (from $12.45^{\circ}$ to $8.13^{\circ}$ ), and at maximum knee flexion (from $16.16^{\circ}$ to $10.67^{\circ}$ ) during DVJ. Furthermore, the mean value of the maximum knee flexion (from $95.00^{\circ}$ to $97.73^{\circ}$ ) and the mean score of the 
Table 2. ICC, the equality of variance (Levene's test) and the effects of pre-test and the effects of groups on the post-test

\begin{tabular}{|c|c|c|c|c|c|c|c|c|c|}
\hline \multirow{3}{*}{ Variable } & \multirow{3}{*}{ ICC } & \multirow{2}{*}{\multicolumn{2}{|c|}{ Levene's Test }} & \multirow{2}{*}{\multicolumn{2}{|c|}{ Pre-Test Effects }} & \multirow{2}{*}{\multicolumn{2}{|c|}{ Training Effects }} & \multicolumn{2}{|c|}{ Paired-Samples T-Test } \\
\hline & & & & & & & & Control & Training \\
\hline & & Sig. & $\mathbf{F}$ & Sig. & $\mathbf{F}$ & Sig. & $\mathbf{F}$ & Sig. & Sig. \\
\hline Y Balance total & 0.88 & 0.41 & 1.89 & 0.01 & 0.88 & 0.01 & 0.82 & 0.80 & 0.01 \\
\hline Single hop & 0.92 & 0.16 & 2.01 & 0.01 & 0.98 & 0.01 & 0.87 & 0.29 & 0.01 \\
\hline Triple hop & 0.85 & 0.20 & 1.72 & 0.01 & 0.98 & 0.01 & 0.89 & 0.29 & 0.01 \\
\hline Crossover hop & 0.84 & 0.43 & 1.90 & 0.01 & 0.99 & 0.01 & 0.75 & 0.62 & 0.01 \\
\hline 6-meter timed hop & 0.87 & 0.62 & 0.25 & 0.01 & 0.98 & 0.01 & 0.95 & 0.57 & 0.01 \\
\hline MKD (pre-land frame) & 0.91 & 0.70 & 0.14 & 0.01 & 0.62 & 0.01 & 0.71 & 0.16 & 0.01 \\
\hline MKD (land frame) & 0.94 & 0.37 & 0.83 & 0.01 & 0.77 & 0.01 & 0.86 & 0.18 & 0.01 \\
\hline Flexion (pre-land frame) & 0.91 & 0.11 & 2.57 & 0.01 & 0.66 & 0.53 & 0.05 & 0.15 & 0.85 \\
\hline Flexion (land frame) & 0.95 & 0.06 & 3.98 & 0.01 & 0.61 & 0.92 & 0.01 & 0.63 & 0.03 \\
\hline
\end{tabular}

knee flexion in the initial contact (from $30.13^{\circ}$ to $30.26^{\circ}$ ) increased; however, that was not statistically significant. These results are consistent with some studies and inconsistent with some other. Herrington reported that 4 weeks of plyometric training can significantly reduce the mean knee valgus angle during drop jump in the left $\left(9.8^{\circ}\right)$, and right $\left(12.3^{\circ}\right)$ legs; and during the jump shot, in the left $\left(4.5^{\circ}\right)$ and the right $\left(4.3^{\circ}\right)$ legs in basketball players [25].

Kato reported that two weeks of neuromuscular training significantly reduced the peak knee angle in the coronal plane (from $9.36^{\circ}$ to $1.15^{\circ}$ ) in basketball players [26]. In a different study on high school players, a significant reduction was observed in the mean MKD values after sports-metric exercises in basketball $(6 \mathrm{~cm})$ [22], volleyball $(4.8 \mathrm{~cm})$ [27], female basketball (13.3 cm) [28], and soccer $(8.5 \mathrm{~cm})$ [29] players. In contrast, many other studies reported the insignificant effect of training interventions on MKD improvement during the landing task $[19,21,31,32]$.

In most studies, plyometric or balance training programs were conducted on targeted hip muscle groups. However, the present intervention program mostly focused on ankle joint strength and flexibility. Therefore, it is recommended that ankle training be included as part of a comprehensive program in MKD exercise interventions. Furthermore, in the present study, subjects with MKD were selected. But in the previous research [19, 21, 31-33], regardless of whether the subject has a neuromuscular impairment or not, the exercise protocol was applied.

Table 3. The demographic data of all athletes in the training and control groups

\begin{tabular}{|c|c|c|c|}
\hline \multirow{2}{*}{ Variable } & \multicolumn{3}{|c|}{ Mean \pm SD } \\
\hline & Train=16 & Cont=16 & All=32 \\
\hline Age (y) & $20.6 \pm 1.9$ & $21.0 \pm 1.6$ & $20.8 \pm 1.7$ \\
\hline Weight (kg) & $74.8 \pm 5.8$ & $73.3 \pm 4.5$ & $74.0 \pm 5.2$ \\
\hline Height (m) & $1.84 \pm 0.05$ & $1.83 \pm 0.04$ & $1.83 \pm 0.50$ \\
\hline BMI $\left(\mathrm{kg} / \mathrm{m}^{2}\right)$ & $22.0 \pm 1.2$ & $21.6 \pm 1.1$ & $21.8 \pm 1.1$ \\
\hline Background & $8.6 \pm 1.4$ & $8.8 \pm 1.4$ & $8.7 \pm 1.4$ \\
\hline
\end{tabular}




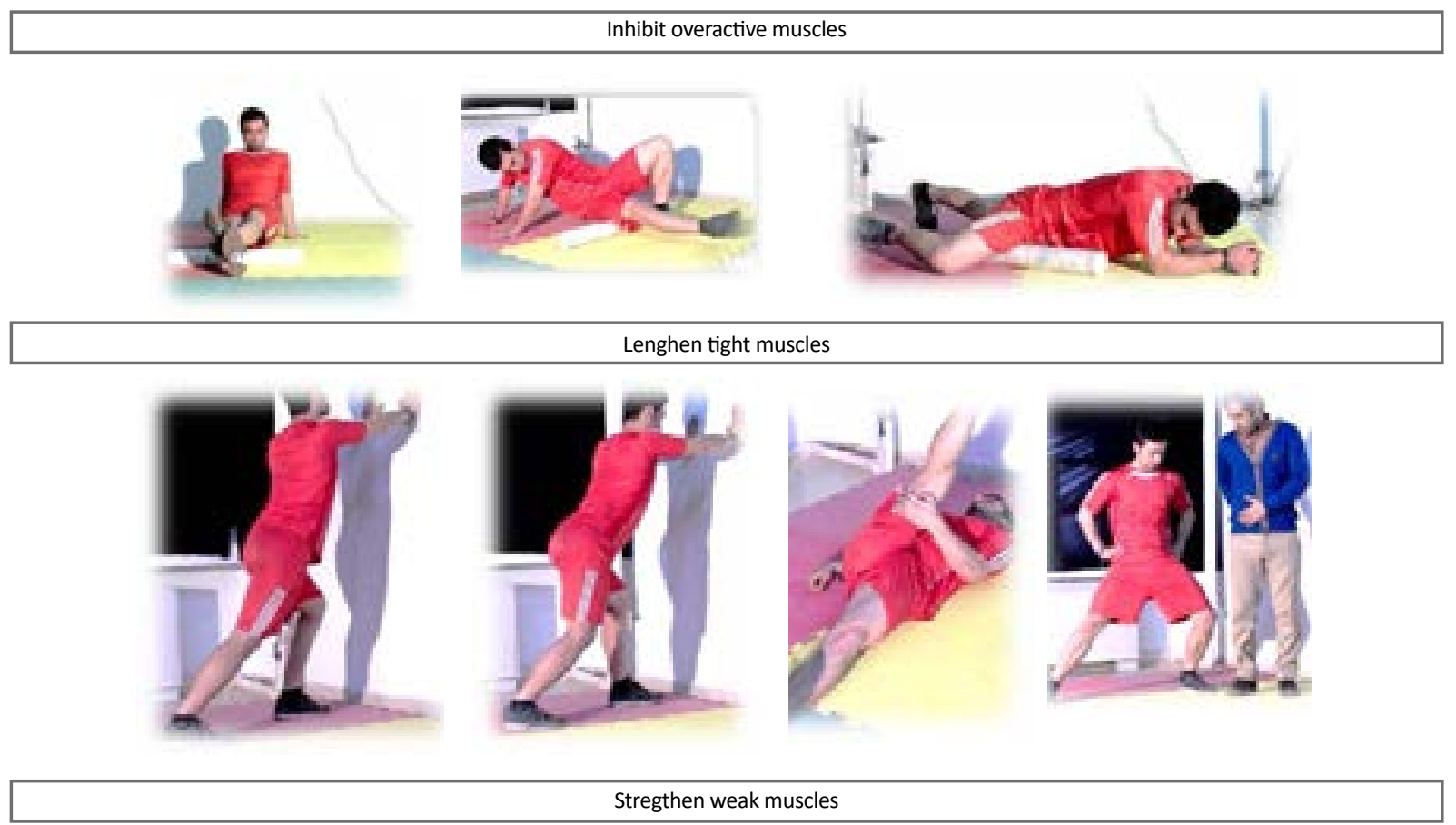

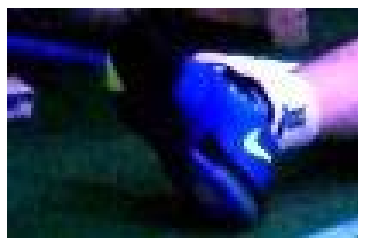

Finish

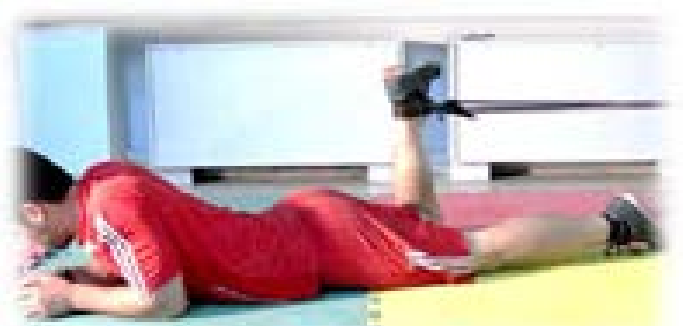

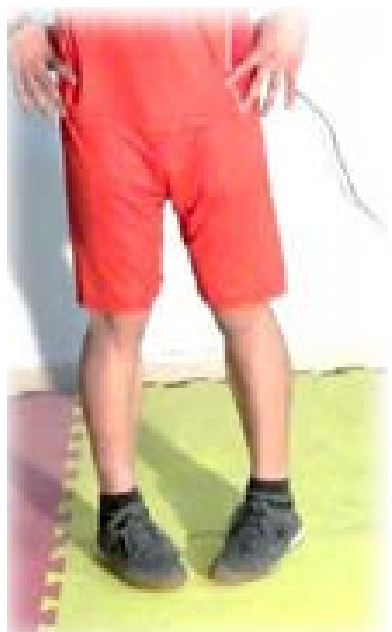

Finish

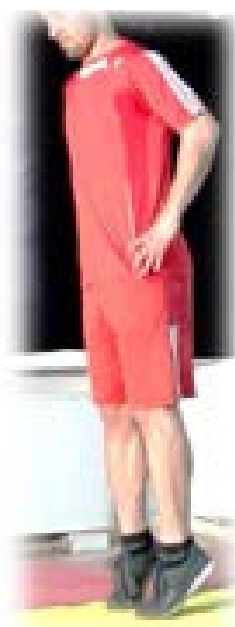

Start

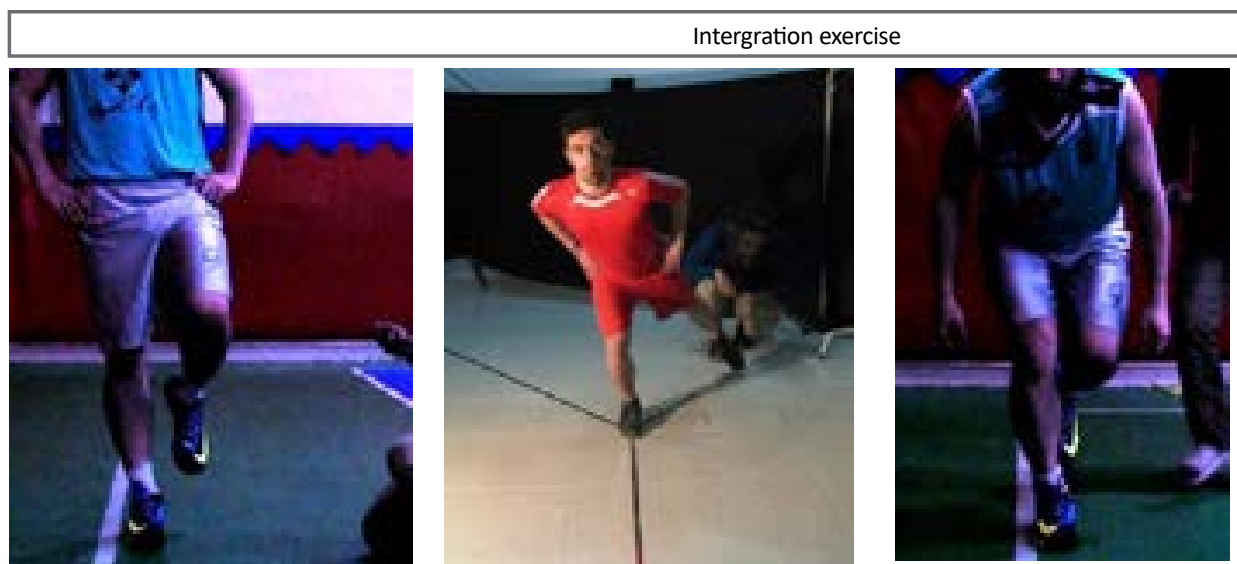

Finish

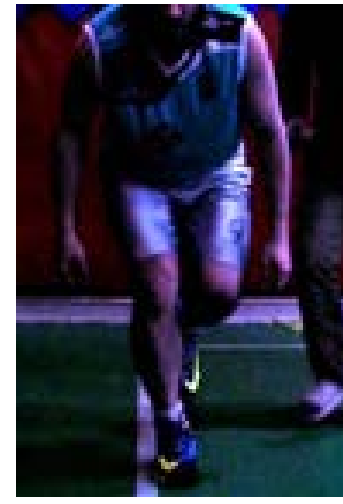

Start

Figure 4. Corrective exercises program

PHYSICAL TREA 


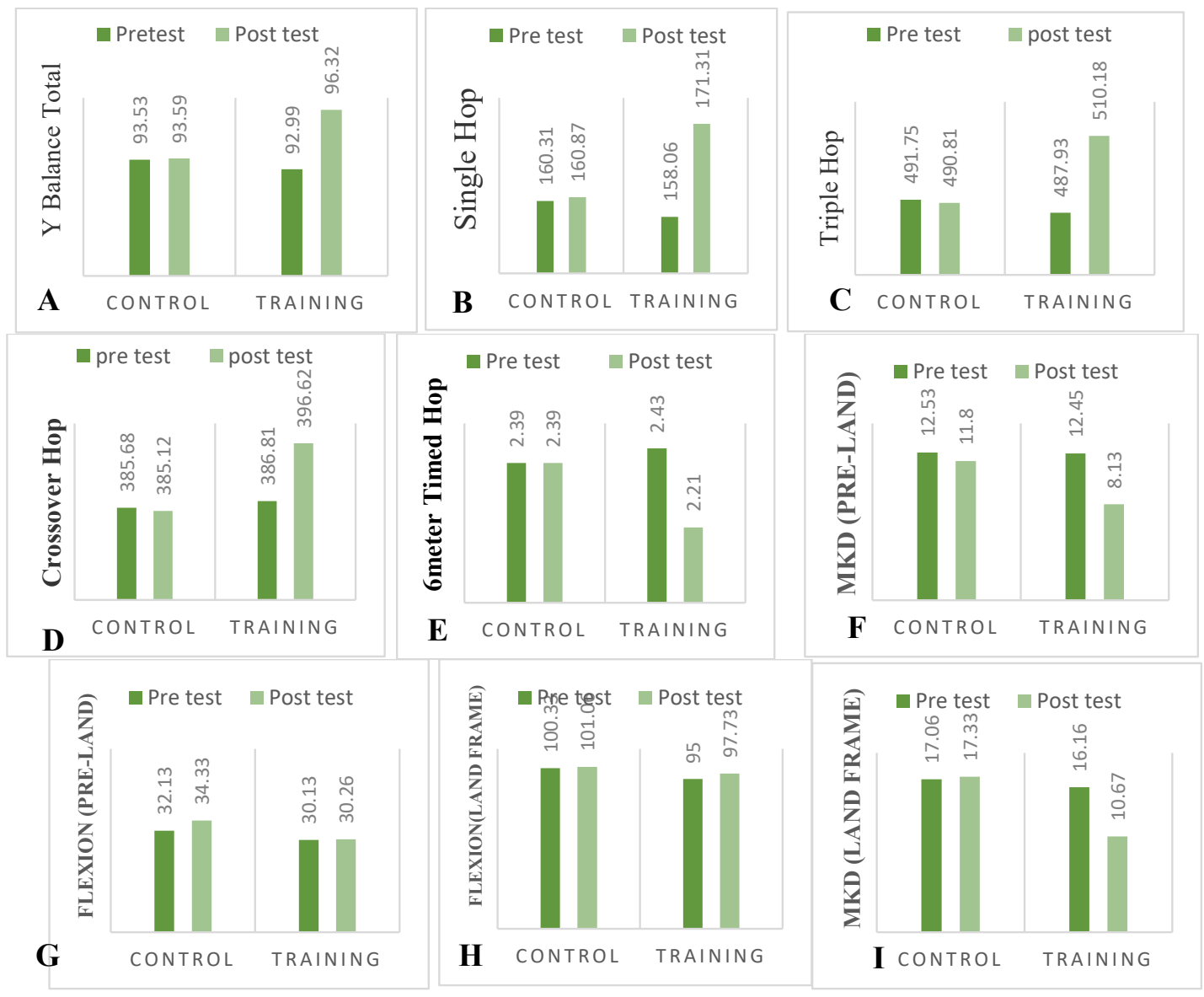

Figure 4. Mean $\pm S D$ of study variables

A. Total Y balance; B. Single hop; C. Triple hop; D. Crossover hop; E. 6-meter timed hop; F. Pre-land MKD; G. Land MKD; H. Pre-land flexion; and I. Land flexion

A prospective study was performed on neuromuscular control kinematics during a jump-landing task in 205 athletes (soccer, basketball, and volleyball). The achieved data demonstrated that athletes with increased dynamic knee valgus are at the increased risk of ACL injury. This is because MKD angle at landing was $8^{\circ}$ greater in ACL-injured, compared to uninjured athletes $(\mathrm{P}<0.05)$ [2]. The video analysis of knee motion during noncontact ACL injury in basketball athletes during a 12-year period (1995 to 2007) introduced MKD as the most important component of ACL injury mechanism [32]. In this study, after participation in the corrective exercise program, the mean MKD angle demonstrated a significant reduction $(\mathrm{P}<0.01)$ at initial contact $(4.32)$ and at maximum knee flexion (6.51) during DVJ; therefore, the corrective exercise protocol of the present study could be successful in preventing the knee injuries of basketball athletes with dynamic knee valgus.

The protocol of the present study consisted of 4 techniques, as follows: release technique to inhibit overactive muscles and release stress or reduce the excessive activity of neuromyofascial tissues; stretching technique to lengthen tight muscles, and increase elasticity, length, and the range of motion of tissues with stiffness; strengthening techniques to reinforce weak muscles and retrain or enhance the activation of low-active tissues; and integrative exercise techniques to retrain the synergistic collective action of all the muscles by progressive functional movements [24]. Inhibiting overactive muscles was performed for lateral gastrocnemius, lateral hamstring (biceps femoris), and adductors muscles. Lengthening tight muscles was performed for lateral gastrocnemius, soleus, lateral biceps femoris, and adductors muscles.

Strengthening weak muscles was performed for medial gastrocnemius, medial hamstring (semimembranosus, semitendinosus), and tibialis posterior muscles. Finally, integrative techniques were conducted with the purpose of retraining the synergistic collective action of all the muscles [15]. Two exercises of three strengthening weak muscles (heel raise and medial hamstring) are similar to DVJ activity and are predominantly performed on the 
sagittal plane. All of the integrative exercises (e.g. single leg balance, single leg hop) are also predominantly performed on the sagittal plane. During integrative exercises, retraining the synergistic collective action of all the muscles can lead to the transfer improvement of the distal (ankle) and proximal (hip) joints to the knees, which may also improve knee alignment in the sagittal plane and reduce MKD (dynamic knee valgus) [15, 24].

In a different study, significant increases in mean knee flexion values at initial contact and maximum knee flexion during DVJ after an exercise program have been reported. Those included significant increases in the mean knee flexion value at initial contact from 29 to 35 in soccer and basketball players [19], and from 27.2 to 28.5 in recreational athletes [30]. In addition, significant increases in the mean maximum knee flexion values from 81 to 86 in soccer and basketball players, and from 92.6 to 94.2 in basketball athletes have been detected $[19,33$, 34]. In contrast, many other studies reported that exercise programs have no significant effects on knee flexion improvement during landing task [26, 30, 35].

In this study, the increased mean value of maximum knee flexion from $95.00^{\circ}$ to $97.73^{\circ}$ was not statistically significant. Another key mechanism of an ACL injury is landing with knee extension [12]. Because the landing with knee position is close to full extension, increased tibia anterior shear force during landing, and can result in ACL rupture [36]. Knee flexion angles were investigated in this study, despite the fact that the exercise protocol was designed to correct MKD. It seems that basketball players' MKD resulted from the weakness and stiffness of the ankle muscles. The exercises protocol was designed to correct it. Moreover, basketball players had no quadriceps dominance; therefore, the studied corrective exercise program had no significant effect $(\mathrm{P}=0.85)$ on knee flexion during DVJ.

The studied basketball players demonstrated significant improvements $(\mathrm{P}<0.01)$ in performance variables such as increased total $\mathrm{Y}$ balance test score $(3.33 \mathrm{~cm})$, increased single hop test distance $(13.25 \mathrm{~cm})$, increased triple hop test distance $(22.25 \mathrm{~cm})$, increased crossover hop test distance $(19.81 \mathrm{~cm})$, and reduced $(0.23 \mathrm{~s})$ 6-meter timed hop test scores. In a different study, significant increases in balance and hop test after intervention training have been reported [19, 25, 37-40]. They included significantly improved balance in high school basketball players, handball players, competitive junior tennis players, and significant improvements in hop test like increased single-leg triple crossover hop distance $(110-111 \mathrm{~cm})$ in basketball players, increased single-leg triple crossover hop distance (right $36.3 \mathrm{~cm}$ and left 36.1 $\mathrm{cm})$ in junior tennis players, and significant reduction in 6-meter timed hop test scores (left $0.14 \mathrm{~s}$ and right 0.17 s) in soccer and basketball players, and increased singleleg hop distance (right $10.39 \mathrm{~cm}$ and left $8.53 \mathrm{~cm}$ ) in basketball, soccer, and volleyball players [19, 25, 37-40].

In this study, the final stage of corrective exercises were integrative exercise techniques. These exercises were performed to retrain the synergistic collective action of all muscles; therefore, retrain the motor system to functional movements pattern (retaining knee position on the frontal plate and modifying the MKD). The use of multi-joint exercise by helping to restore neuromuscular control can improve the coordination among activated muscles [24]. Performing dynamic integrative exercises (i.e. balance and hop) by enhancing the multi-plane muscle control, improved the functional capacity of the motor system. To achieve desirable multi-articular movements (e.g. hop and balance tests in this study), higher muscular coordination is required; moreover, performing these exercises increases muscle coordination [41]. Overall, in the present study, improvements in performance (balance and hop) after conducting corrective exercises were expected because these tests were part of the exercise program.

According to the literature, pilot study and initial screening, the studied basketball players had stiffness in lateral gastrocnemius, soleus, biceps femoris, and adductors muscles, and had weakness in medial gastrocnemius, medial hamstring, and tibialis posterior muscles, due to MKD [15-17]. Heel raise during DLS resulted in ankle plantarflexion position and increased the ankle dorsiflexion range of motion during DLS [16]. Due to modifying the restriction of dorsiflexion range of motion, the DLS knee can remain in the direction of the toes. Lower leg muscles imbalance, like the ankle muscle stiffness (lateral gastrocnemius, soleus, peroneal), can result in the abduction and external rotation of the tibia and consequently dynamic knee valgus. In addition, the weakness of the medial gastrocnemius and tibialis anterior and tibialis resulted in reduced knee valgus motion and ability to control foot pronation, and consequently excessive MKD [15-17, 41].

The corrective exercise protocol of the present study, in addition to modifying the $\mathrm{MKD}$, improves the performance of basketball players. It can help to prevent noncontact ACL injury as well as other associated knee and ankle noncontact injuries occurring due to the MKD. This is because the training group experienced a better landing kinematic and improved MKD during the DVJ 
The modified kinematics DVJ can improve the key risk factors of a noncontact knee injury and can help to prevent lower extremity injury in basketball players with dynamic knee valgus.

We investigated the effect of a selected corrective exercises program. These exercises can significantly improve the kinematic of the knee during DVJ and performance. Due to MKD correction which is the key risk factors of noncontact ACL injury, we observed improvements in landing kinematic and performance; thus, male basketball players with MKD may benefit from this corrective exercises program to prevent noncontact knee injuries caused by MKD during a functional activity like DVJ. It can also help improve their performance.

\section{Ethical Considerations}

\section{Compliance with ethical guidelines}

All athletes read and signed a written informed consent before testing and completing a detailed injury history. The study participants were informed about the purpose of the research and its implementation stages; they were also assured about the confidentiality of their information. Moreover, they were allowed to discontinue the study whenever they wished, and if desired, the results of the research would be available to them.

\section{Funding}

This research did not receive any specific grant from funding agencies in the public, commercial, or not-forprofit sectors.

\section{Authors' contributions}

All authors contributed in designing, running, and writing all parts of the research.

\section{Conflict of interest}

The authors declared no conflict of interest.

\section{References}

[1] Chuter VH, Janse de Jonge X. Proximal and distal contributions to lower extremity injury: A review of the literature. Gait \& Posture. 2012; 36(1):7-15. [DOI:10.1016/j.gaitpost.2012.02.001] [PMID]

[2] Hewett TE, Myer GD, Ford KR, Heidt RS, Colosimo AJ McLean SG, et al. Biomechanical measures of neuro- muscular control and valgus loading of the knee predict anterior cruciate ligament injury risk in female athletes. American Journal of Sports Medicine. 2005; 33(4):492-501. [DOI:10.1177/0363546504269591] [PMID]

[3] Rosa BB, Asperti AM, Helito CP, Demange MK, Fernandes TL, Hernandez AJ. Epidemiology of sports injuries on collegiate athletes at a single center. Acta Ortopedica Brasileira. 2014; 22(6):321-4. [DOI:10.1590/1413-78522014220601007] [PMID] [PMCID]

[4] Mihelic R, Jurdana H, Jotanovic Z, Madjarevic T, Tudor A Long-term results of anterior cruciate ligament reconstruction: a comparison with non-operative treatment with a follow-up of 17-20 years. International Orthopaedics. 2011 35(7):1093-7. [DOI:10.1007/s00264-011-1206-x] [PMID] [PMCID]

[5] Noyes FR, Barber-Westin S. The ACL: Anatomy, biomechanics, mechanisms of injury, and the gender disparity: Causes, impacts, and conditioning programs. In: Noyes F, BarberWestin S, editors. ACL Injuries in the Female Athlete. Berlin: Springer; 2018. [DOI:10.1007/978-3-662-56558-2_1]

[6] Sanders TL, Maradit Kremers H, Bryan AJ, Larson DR, Dahm DL, Levy BA, et al. Incidence of anterior cruciate ligament tears and reconstruction: A 21-year population-based study. American Journal of Sports Medicine. 2016; 44(6):1502-7. [DOI:10.1177/0363546516629944] [PMID]

[7] Chadwick PC, Yung H, Julie R, Brian J, Kelvin S. A metaanalysis of the incidence of anterior cruciate ligament tears as a function of gender, sport, and a knee injury-reduction regimen. Arthroscopy. The Journal of Arthroscopic \& Related Surgery. 2007; 23(12):1320-5. [DOI:10.1016/j.arthro.2007.07.003] [PMID]

[8] Newman JS, Newberg AH. Basketball injuries. Radiologic Clinics. 2010; 48(6):1095-111. [DOI:10.1016/j.rcl.2010.07.007] [PMID]

[9] Yentes JM, Kurz MJ, Stergiou N. Lower extremity injury in female basketball players is related to a large difference in peak eversion torque between barefoot and shod conditions. Journal of Sport and Health Science. 2014; 3(3):227-32. [DOI:10.1016/j.jshs.2012.11.004]

[10] Mohammadi H, Daneshmandi H, Alizadeh MH, Shamsimajlan A. Screening tests for neuromuscular imbalance that affecting the non-contact acl injury. Scientific Journal of Kurdistan University of Medical Sciences. 2015; 20(2):85-105. [DOI:10.22102/20.2.85]

[11] Mohammadi H, Daneshmandi H, Alizadeh MH, Shamsimajlan A. [The effect of ACL intervention programs on the improvement of neuromuscular deficiencies and reducing the incidence of ACL injury (Persian)]. Journal of Rehabilitation Medicine. 2015; 4(2):159-69.

[12] Quatman CE, Quatman CC, Hewett TE. A plane explanation of anterior cruciate ligament injury mechanisms: A systematic review. Sports Medicine. 2010; 40(9):729-46. [DOI:10.2165/11534950-000000000-00000] [PMID]

[13] Hewett TE, Ford KR, Hoogenboom BJ, Myer GD. Understandin and prevention ACL injuries: Current biomechanical and epidemiological consideration. North American Journal of Sports Physical Therapy. 2010; 5(4):234-51. [PMID] [PMCID] 
[14] Ford KR, Myer GD, Hewett TE. Valgus knee motion during landing in high school female and male basketball players. Medicine \& Science in Sports \& Exercise. 2003; 35(10):174550. [DOI:10.1249/01.MSS.0000089346.85744.D9] [PMID]

[15] Bell DR, Clark MA, Padua DA. Two- and 3-dimensional knee valgus are reduced after an exercise intervention in young adults with demonstrable valgus during squatting. Journal of Athletic Training. 2013; 48(4):442-9. [DOI:10.4085/1062-6050-48.3.16] [PMID] [PMCID]

[16] Mohammadi H, Daneshmandi H, Alizadeh M, Shamsi Majlan A. [The effect of dynamic knee valgus during overhead squat on distal and proximal knee joints muscle strength and range of motion in basketball players (Persian)]. Journal of Sport Biomechanics. 2018; 3(4):17-27.

[17] Hirth CJ, Padua DA. Clinical movement analysis to identify muscle imbalances and guide exercise. Athletic Therapy Today. 2007; 12(4):10-4. [DOI:10.1123/att.12.4.10]

[18] Smith LJ, Creps JR, Bean R, Rodda B, Alsalaheen B. Performance and reliability of the $\mathrm{Y}$-Balance Test ${ }^{\mathrm{TM}}$ in high school athletes. Journal of Sports Medicine and Physical Fitness. 2018; 58(11):1671-5. [DOI:10.23736/S0022-4707.17.07218-8]

[19] Chappell JD, Limpisvasti O. Effect of a neuromuscular training program on the kinetics and kinematics of jumping tasks. American Journal of Sports Medicine. 2008; 36(6):10816. [DOI:10.1177/0363546508314425] [PMID]

[20] Mani K, Brechue WF, Friesenbichler B, Maffiuletti NA. Validity and reliability of a novel instrumented one-legged hop test in patients with knee injuries. The Knee. 2017; 24(2):23742. [DOI:10.1016/j.knee.2016.09.004] [PMID]

[21] Nagano Y, Ida H, Akai M, Fukubayashi T. Biomechanical characteristics of the knee joint in female athletes during tasks associated with anterior cruciate ligament injury. The Knee. 2009; 16(2):153-8. [DOI:10.1016/j.knee.2008.10.012] [PMID]

[22] Noyes FR, Barber-Westin SD, Fleckenstein C, Walsh C, West J. The drop-jump screening test: Difference in lower limb control by gender and effect of neuromuscular training in female athletes. American Journal of Sports Medicine. 2005; 33(2):197-207. [DOI:10.1177/0363546504266484] [PMID]

[23] Huston LJ, Vibert B, Ashton-Miller JA, Woitys EM. Gender differences in knee angle when landing from a dropjump. American Journal of Knee Surgury. 2001; 14(4):215-9. [PMID]

[24] Clark M, Lucett S, National Academy of Sports Medicine. NASM essentials of corrective exercise training. Philadelphia: Lippincott Williams \& Wilkins; 2010.

[25] Herrington L. The effects of 4 weeks of jump training on landing knee valgus and crossover hop performance in female basketball players. Journal of Strength and Conditioning Research. 2010; 24(14):3427-32. [DOI:10.1519/ JSC.0b013e3181c1fcd8] [PMID]

[26] Kato S, Urabe Y, Kawamura K. Alignment control exercise changes lower extremity movement during stop movements in female basketball players. The Knee. 2008; 15(4):299-304. [DOI:10.1016/j.knee.2008.04.003] [PMID]

[27] Noyes FR, Barber-Westin SD, Smith ST, Campbell T. A training program to improve neuromuscular indices in fe- male high school volleyball players. Journal of Strength and Conditioning Research. 2011; 25(8):2151-60. [DOI:10.1519/ JSC.0b013e3181f906ef] [PMID]

[28] Noyes FR, Barber-Westin SD, Smith ST, Campbell T, Garrison TT. A training program to improve neuromuscular and performance indices in female high school basketball players. Journal of Strength and Conditioning Research. 2012 26(3):709-19. [DOI:10.1519/JSC.0b013e318228194c] [PMID]

[29] Noyes FR, Barber-Westin SD, Tutalo Smith ST, Campbell T. A training program to improve neuromuscular and performance indices in female high school soccer players. Journal of Strength and Conditioning Research. 2013; 27(2):340-51. [DOI:10.1519/JSC.0b013e31825423d9] [PMID]

[30] Herman DC, Weinhold PS, Guskiewicz KM, Garrett WE, Yu B, Padua DA. The effects of strength training on the lower extremity biomechanics of female recreational athletes during a stop-jump task. American Journal of Sports Medicine 2008; 36(4):733-40. [DOI:10.1177/0363546507311602] [PMID]

[31] Herman DC, Oñate JA, Weinhold PS, Guskiewicz KM, Garrett WE, Yu B, et al. The effects of feedback with and without strength training on lower extremity biomechanics. American Journal of Sports Medicine. 2009; 37(7):1301-8. [DOI:10.1177/0363546509332253] [PMID]

[32] Lephart SM, Abt JP, Ferris CM, Sell TC, Nagai T, Myers JB, Irrgang JJ. Neuromuscular and biomechanical characteristic changes in high school athletes: A plyometric versus basic resistance program. British Journal of Sports Medicine. 2005; 39(12):932-8. [DOI:10.1136/bjsm.2005.019083] [PMID] [PMCID]

[33] Hewett TE, Torg JS, Boden BP. Video analysis of trunk and knee motion during non-contact anterior cruciate ligament injury in female athletes: Lateral trunk and knee abduction motion are combined components of the injury mechanism. British Journal of Sports Medicine. 2009; 43(6):417-22. [DOI:10.1136/bjsm.2009.059162] [PMID] [PMCID]

[34] Lim BO, Lee YS, Kim JG, An KO, Yoo J, Kwon YH. Effects of sports injury prevention training on the biomechanical risk factors of anterior cruciate ligament injury in high school female basketball players. American Journal of Sports Medicine. 2009; 37(9):1728-34. [DOI:10.1177/0363546509334220] [PMID]

[35] Barendrecht M, Lezeman HC, Duysens J, Smits-Engelsman BC. Neuromuscular training improves knee kinematics, in particular in valgus aligned adolescent team handball players of both sexes. Journal of Strength and Conditioning Research. 2011; 25(3):575-84. [DOI:10.1519/ JSC.0b013e3182023bc7] [PMID]

[36] Sell TC, Ferris CM, Abt JP, Tsai YS, Myers JB, Fu FH, et al Predictors of proximal tibia anterior shear force during a vertical stop-jump. Journal of Orthopaedic Research. 2007; 25(12):1589-97. [DOI:10.1002/jor.20459] [PMID]

[37] McLeod TC, Armstrong T, Miller M, Sauers JL. Balance improvements in female high school basketball players after a 6-week neuromuscular-training program. Journal of Sport Rehabilitation. 2009; 18(4):465-81. [DOI:10.1123/jsr.18.4.465] [PMID]

[38] Holm I, Fosdahl MA, Friis A, Risberg MA, Myklebust G, Steen $\mathrm{H}$. Effect of neuromuscular training on proprioception, balance, muscle strength, and lower limb function in female team handball players. Clinical Journal of Sport Med- 
icine. 2004; 14(2):88-94. [DOI:10.1097/00042752-20040300000006] [PMID]

[39] Barber-Westin SD, Hermeto AA, Noyes FR. A 6-week neuromuscular training program for competitive junior tennis players. Journal of Orthopaedic Research. 2010; 24(9):237282. [DOI:10.1519/JSC.0b013e3181e8a47f] [PMID]

[40] Myer GD, Ford KR, Palumbo JP, Hewett TE. Neuromuscular training improves performance and lower-extremity biomechanics in female athletes. Journal of Orthopaedic Research. 2005; 19(1):51-60. [DOI:10.1519/13643.1] [PMID]

[41] Vesci BJ, Padua DA, Bell DR, Strickland LJ, Guskiewicz $\mathrm{KM}$. Influence of hip muscle strength, flexibility of hip and ankle musculature, and hip muscle activation on dynamic knee valgus during a double-legged squat. Journal of Athletic Training. 2007; 42:S-83. 
This Page Intentionally Left Blank 